\title{
EL TRÁILER EN LA INDUSTRIA CINEMATOGRÁFICA ESPAÑOLA: ANÁLISIS DE CASOS DE LAS DÉCADAS DE LOS 50, 60,70 Y 80
}

Eva María Gil-Pons 1: Universidade da Coruña. España eva.gil@udc.es

\section{RESUMEN}

La presente investigación es una aproximación a la evolución que ha experimentado el tráiler en la industria cinematográfica española, la cual tiene unas particularidades propias que se manifiestan en la principal pieza de marketing cinematográfico, el tráiler. Para trazar esta evolución se estudian casos particulares de trailers de las décadas de los años 50, 60, 70 Y 80 estableciendo además el marco cinematográfico que caracteriza esa determinada época y los vínculos que se establecen entre el discurso cinematográfico propio de esos años y el discurso del tráiler.

PALABRAS CLAVE: Tráiler - Cine español - Retórica - Narrativa

\section{THE TRAILER IN THE SPANISH FILM INDUSTRY: CASE ANALYSIS OF THE 50s, 60s AND 70s DECADES}

\begin{abstract}
This research is an approach to the evolution experienced by the trailer in the Spanish film industry, which has some special characteristics that are manifested in the main piece of film marketing, the trailer. To trace this evolution are studied particular cases of trailers from the decades of the 50, 60, 70 and 80 . The research also outlines the context that characterizes this period of cinema in particular and the links established between the cinematic discourse typical of those years and the discourse of the trailer.
\end{abstract}

KEY WORDS: Trailer - Spanish Cinema - Rhetoric - Narrative

\footnotetext{
${ }^{1}$ Autor correspondiente

Eva María Gil-Pons: Contratada María Barbeito en la Universidade da Coruña, España.

Correo: eva.gil@udc.es
} 


\section{INTRODUCCIÓN}

Los trailers son una pieza clave en el funcionamiento de la industria cinematográfica, una herramienta de marketing que posiciona un film en el mercado. A pesar de que a priori puede considerarse que un tráiler es un spot publicitario convencional de un estreno cinematográfico, lo cierto es que tiene unas peculiaridades que hacen que tenga una entidad propia y que puedan ser considerados objetos unificados de naturaleza homogénea.

El objetivo de esta investigación es establecer el recorrido que ha experimentado el tráiler cinematográfico en el caso concreto de la industria española. Este trayecto, a pesar de responder a las especificidades propias del contexto cinematográfico español, no puede entenderse sin la evolución que presenta en tráiler en la industria de Hollywood, que ha sentado desde el comiendo las bases de la estética del tráiler.

"Los trailers son películas perfectas porque nunca te llegan a defraudar" (Jean-Luc Godard

\section{DESARROLLO}

\subsection{Una aproximación al tráiler de cine}

Los trailers ocupan un lugar clave en la fase de comunicación y promoción de las películas. Mediante esta pieza audiovisual promocional, el espectador conoce la existencia de un film determinado y le atribuye unas características que le permiten distinguirlo del resto de películas de la cartelera (Kuehn, 2005). El tráiler persigue fundamentalmente tres objetivos: en primer lugar, informar sobre la existencia de una película determinada y de su próximo estreno. En segundo lugar, crear expectación en el espectador sobre la película que anuncia y, por último, transmitir el estilo de la película, principalmente su estética y su temática (Sánchez Puche, 2008).

No existe un modelo único de tráiler, sino que éste depende sobre todo del género del film que anuncia y de los objetivos comunicativos que persigue. Tal y como apunta Claudia Melissa Neves, el tráiler, a pesar de que puede ser visto como una versión reeditada y reducida del film, "posee una estructura y narrativa propia, generando significación y posibilidad de reconstrucción" (Neves, 2004). Actualmente hay una cierta homogenización en la edición de los avances cinematográficos que viene marcada por las necesidades de la industria. Se produce así una estandarización que suelen recurrir a fórmulas establecidas con escenas llamativas, diálogos que descubren la trama principal de la película, la presentación de los personajes protagonistas, una potente banda sonora agitada y una narración en off o insertos de texto que apuntan información de interés para el espectador (como referencias a anteriores obras del director de la película o el libro en el que se basa el film promocionado). 
Los trailers pueden adoptar formas muy diversas. Jon Dornaleteche (2007) establece una interesante clasificación según sus características formales y distingue entre: teaser trailer, creative trailer, clip trailer, theatrical trailer, tv trailer, behind the scenes trailer y video game tráiler. A esta clasificación se le pueden sumar otras manifestaciones aparecidas en los últimos tiempos, los handmade trailers. Éstos nacen gracias al acceso que los usuarios tienen a las nuevas herramientas de edición digital y a portales en Internet, como Youtube o Megavideo, que hacen que el espectador pueda compartir en la Red sus creaciones audiovisuales realizadas a partir de materiales de películas y trailers originales. Dentro de este fenómeno destacan los recut, los mash-up trailers y los fake trailers, textos instalados en la cultura colaborativa digital que constituyen una relectura del tráiler cinematográfico tradicional. Los usuarios desvían los significados originales de los textos matriz e imponen nuevas narrativas a través de una reutilización y reconstrucción de los materiales preexistentes (Dornaleteche y Gil, 2011).

El presente trabajo se detiene en el theatrical trailer, que es el modelo de tráiler por antonomasia. Éste es el más frecuente en las salas de cine, de ahí el término theatrical, que proviene de theather (teatro), que en inglés hace referencia a las salas de cine. Se trata del tráiler estándar para la industria cinematográfica por su duración (de dos minutos a dos minutos y medio) y sus características fundamentales son el montaje discontinuo y el uso de imágenes de la película promocionada que muestran la trama de la película a través de la presentación de su programa narrativo. Éste introduce el personaje protagonista de la película, los núcleos principales de la trama, las fuerzas antagonistas, el tema que abordará el film y ofrece una idea general de la estética y la banda sonora de la película. Además, presenta material extradiegético como el nombre del director, de los actores principales del reparto, el título de la película, la fecha de estreno e información de especial relevancia para el espectador como los premios conseguidos por la película.

\subsection{Breve historia del tráiler en EEUU}

El tráiler ha evolucionado paralelamente a la industria cinematográfica. Existen grandes diferencias entre las primitivas piezas promocionales (fragmentos de películas ofrecidos al final de las proyecciones en las salas de cine) y los actuales trailers, considerados la principal pieza del marketing cinematográfico. Pocos son los trabajos académicos que se centran en la historia de esta pieza audiovisual promocional. Pueden destacarse las investigaciones de Vinzenz Hediger ${ }^{2}$, Lisa Kernan ${ }^{3}$ y, en el

\footnotetext{
${ }^{2}$ HedigeR, V. (2003). A cinema of memory in the future tense: Godard, trailers and Godard trailers. En Williams, J., Temple, M. \& Witt, M.(Eds).. Forever Godard: the work of Jean- Luc Godard, 1950 to the present, Londres, Black Dog Publishing.

(1999): «The narrative turn in film advertising: on the physiognomy of contemporary trailers». Presentado en You can have it: Kinorituale, Viena

${ }^{3}$ Kernan, L. (2004). Coming Attractions: Reading American Movie Trailers. Press: University of Texas
} 
ámbito español, el estudio de Dornaleteche ${ }^{4}$. Todos estos trabajos se centran en la en la historia del tráiler en los EE. UU. Además, otra de las referencias más importantes en este tema es el documental producido por la fundación Andrew J. Kuehn (http://www.ajkfoundation.org/), «Coming attractions: The history of movie trailers» (2005). Por lo que respecta a la cinematografía española, no existe ningún trabajo académico que se detenga en la evolución que ha experimentado la estrategia retórica del tráiler en nuestro país.

Tal y como señala Axel Bucker, "la historia del tráiler atraviesa la historia del cine, más precisamente la historia del público del cine". El tráiler nace con la necesidad de las productoras de anunciar sus próximos estrenos cuando el cinematógrafo deja de ser un espectáculo por sí mismo y su público se torna más selectivo con las producciones. Kevin Thomas (1966) afirma que el primer tráiler fue exhibido en 1912 en Nueva York 5 .

Los exhibidores pusieron en práctica primitivas estrategias para asegurar el retorno de los espectadores a las salas cinematográficas. Algunos mostraban el comienzo de una película que tenían previsto proyectar en breve una vez finalizado el film principal. Otros seleccionaban las escenas más interesantes o impactantes de un estreno próximo y las unían, proyectado en la sala el resultado.

La primera major en lanzar oficialmente trailers fue la Paramount en 1916. Poco después, en 1919, el estudio creó una sección especializada en la realización de trailers que ya montaba este tipo de piezas para todas sus producciones. En pocos años todas las majors contaban ya con una división especializada en la creación de trailers, reconociendo con ello el potencial que esta nueva forma publicitaria tenía para la promoción cinematográfica. Los trailers en esta época son bastante homogéneos, solían "festejar el espectáculo y las estrellas de forma ampulosa, utilizando títulos en superlativo y narración sorprendente" (Neve, 2004: 60)

Varios son los acontecimientos que van a determinar la evolución del discurso del tráiler. El primero de ellos fue el nacimiento de las trailer houses, agencias especializadas en trailers que se especializaban en distintos géneros y enfoques redefiniendo la estética del tráiler. En la década de los setenta comienza a percibirse el potencial impactante en la promoción cinematográfica de la televisión, que hasta ese momento había sido descuidada por el cine como instrumento publicitario. A principios de los años sesenta apenas existían todavía spots televisivos sobre próximos estrenos fílmicos, pero este hecho va a cambiar sustancialmente gracias a la

\footnotetext{
${ }^{4}$ Dornaleteche, J. (2009). El trailer cinematográfico: historia de un género publicitario en EE. UU. Pensar la Publicidad, vol. III, (1): 163-180.

${ }^{5}$ El tráiler era sobre la serie The adventures of Kathlyn y justo al final de la breve proyección, la protagonista, Kathyn, era apresada en la jaula de un león. A continuación se mostraba el siguiente texto: “¿Escapará de la cueva del león? ¡Vea en las próximas semana esta capítulo vibrante!” (“Does she escape the lion's pit? See next week's thrilling chapter!").
} 
revolución que supuso para la promoción cinematográfica la película Billy Jack (1971, Tom Laughlin) 6 .

La década de los ochenta trajo también importantes cambios a la industria del tráiler. El 1 de agosto de 1981 la cadena norteamericana de televisión MTV estrena su primer videoclip, Video killed radio star. A partir de este momento comienza una profunda reestructuración del tráiler que afectará a cuestiones como la edición, la duración o la El principal motivo para escoger esta fecha como punto de partida es que muchos teóricos la señalan como el comienzo de una nueva etapa. Entre estos autores, José Luis Castro y Jaime Pena apuntan: “Varios factores políticos, económicos, sociales e incluso directamente cinematográficos permiten situar en 1951 el comienzo de un nuevo periodo: el fuerte desarrollo de un capital bancario y la consecuente exigencia de un modelo desarrollista (alejado del aislamiento anterior); el nuevo papel de España en la escena internacional, tras el final de la II Guerra Mundial y el comienzo de la llamada Guerra Fría (lo que trae consigo, por ejemplo, la concesión en el mismo 1950 por parte del Congreso norteamericano de un importante préstamo). También en 1950, en noviembre, la ONU revoca la resolución que recomendaba la retirada de embajadores y en diciembre se nombra el nuevo representante diplomático americano en España" (Castro y Pena, 2005: 33).

En esta década la producción cinematográfica española experimenta un notable incremento en su volumen debido a diversos factores ${ }^{7}$. Este incremento en la producción es el principal motivo de la proliferación de trailers en la industria nacional. Es en esta década donde las películas con mayor presupuesto comienzan a realizar piezas audiovisuales promocionales que se vienen a sumar a los tradicionales métodos publicitarios cinematográficos como los carteles o los programas de mano. Es innegable la influencia de los trailers hollywoodienses en la edición de las piezas promocionales de películas españolas. Muchos rasgos definitorios de los trailers norteamericanos son tomados en nuestra industria adaptándolos a las peculiaridades de la cinematografía nacional.

Respecto al análisis, se atiende a diversos aspectos que permiten una aproximación al modelo de tráiler característico cada década como la banda sonora, la narración en off, el montaje (como elemento responsable de la organización narrativa del mensaje) y,

\footnotetext{
${ }^{6}$ Después de cosechar un escaso éxito en taquilla tras su estreno (dos millones de dólares), el director del film denunció a la productora, la Warner Bros. por una mala distribución de la cinta, forzando al estudio a anunciar la película en televisión a través de una enorme campaña antes de que la cinta llegara de nuevo a las salas de exhibición de todo el país. El resultado de esta operación de marketing de la película fue la recaudación en taquilla de veintidós millones de dólares. Otras películas de estos años, como El exorcista, Tiburón y The Sting, percibieron el potencial de la publicidad televisiva en la promoción cinematográfica y compraron espacios publicitarios en este medio. Estas películas consiguieron en su primer año de distribución más de setenta millones de dólares cada una

${ }^{7}$ Los cambios de las ayudas a la producción o las cuotas de distribución y pantalla, el desabastecimiento de cine norteamericano como consecuencia del boicot de la M.P.E.A., el aumento muy considerable de las coproducciones, el mayor nivel económico de la población con su consecuente aumento en la frecuentación e incluso algunos éxitos comerciales indudables de determinados filmes" (Gubern, Monterde, Perucha, Rimbau y Torreiro, 1995: 255)
} 
por último, la política de promoción, es decir, qué elementos se destacan en el tráiler (director, actores, etc.) con el objetivo de atraer la atención del espectador sobre la película promocionada. Por lo que respecta a la selección de las películas, se ha atendido a diferentes criterios como el éxito conseguido por la película, la relevancia de ésta en la historia del cine español, la originalidad del tráiler o la política de promoción del filme llevada a cabo por la productora.

\subsection{La década de los 50}

Los años cincuenta están marcados en el cine español por el encuentro entre dos generaciones de cineastas. Por un lado jóvenes directores provenientes del Instituto de Investigaciones y Experiencias Cinematográficas, como Berlanga o Bardem, y por otro lado directores veteranos como José Luis Sáenz de Heredia, Rafael Gil o Juan de Orduña. De este encuentro surgen dos concepciones muy diferentes del cine. Bienvenido Míster Marshall, de 1951, se convierte en una de las películas con más trascendencia histórica del cine español. Dirigida por Luis García Berlanga y con un guión del propio Berlanga y Juan Antonio Bardem, con la participación de Miguel Mihura, la historia muestra el malestar que había en España por no haber participado en el reparto de la ayuda americana del Plan Marshall para la reconstrucción de Europa tras la II Guerra Mundial. La productora UNICIA pidió al realizador que hiciera un film folclórico que popularizase a la cantante Lolita Sevilla, pero éste se transformó en una parodia de la vida rural española, al tiempo que hacía una crítica caricaturesca de la España de los años cincuenta.

Otros de los directores más sobresalientes de esta década son Juan Antonio Bardem y José Luis Sáenz de Heredia. Bardem dirige en estos años Muerte de un ciclista (1955) y Calle Mayor (1956), ambos influenciados por el neorrealismo italiano. Sáenz de Heredia, que provenía de la década anterior, dirige Historias de la radio (1955), un homenaje cinematográfico a la radio, medio de entretenimiento e información en torno al cual giraba la vida familiar y social de los años cincuenta.

La película se estructura a partir de tres relatos independientes a modo de sketchs basados en los concursos radiofónicos, todos enlazados por el locutor, Gabriel, y su prometida. El primer relato narra la historia de un inventor (Pepe Isbert) que se disfraza de esquimal para conseguir el premio que le permita patentar su invento. El segundo relato está protagonizado por un ladrón que, mientras roba a su casero para pagar el alquiler, acierta un concurso musical por teléfono. El tercer relato es de un maestro de pueblo que juega a "doble o nada" porque necesita el dinero para que un niño de su pueblo pueda ser operado.

Tal y como apunta Carlos F. Heredero, la fórmula de Historias de la Radio es la del humor blanco urdido en torno a la picaresca urbana, la del ramalazo ilusionista cercano al cuento de hadas, portador de una simpatía contagiosa hacia pillos y granujillas de buen corazón, testigo cósmico y suavemente satírico de las dificultades para sobrevivir en la España protoindustrial que contempla todavía el desarrollo capitalista como una quimera" (Perucha, 1997: 397). 


\subsection{Tráiler de Historias de la radio (1955)}

El tráiler comienza con un grupo de personas con pancartas y cánticos de apoyo a Don Anselmo (en la película un maestro que acude al programa de radio para ganar dinero y poder ayudar a un niño enfermo, para que pueda operarse en el extranjero). Un guardia civil es llevado a hombros por tres aldeanos entre la multitud que avanza hasta llegar a ocupar todo el plano. A continuación aparecen las primeras palabras del tráiler. Se trata de un texto escrito en el que se lee: "USTEDES, claro está" $\backslash$ "Deben ser todos RADIOYENTES" \"Y estarán FAMILIARIZADOS con la radio" \ "Pero no pueden sospechar lo que es" \"La más ORIGINAL PELÍCULA del momento" "HISTORIAS DE LA RADIO". Se trata de una apelación directa al espectador, ("USTEDES”), que además aparece resaltado gracias al uso de las mayúsculas. Busca apelar a la audiencia posicionándola como radioyentes ${ }^{8}$. Posteriormente el texto introduce el objeto que se convertirá en el centro de la película, el lugar en el que confluyen las tres historias que se narran en el film, la radio.

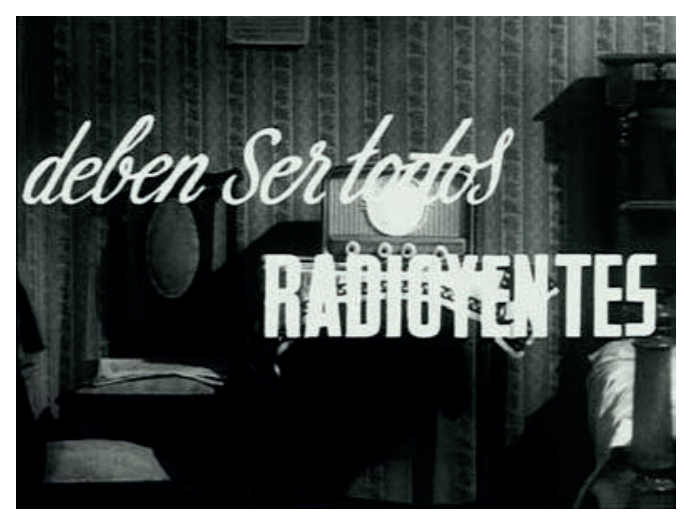

Figura 1. Film narrado en la radio

Tras mostrar vez dos presentadores, Alfredo (Juanjo Menéndez) y Carmen (Margarita Andrey) en una grabación de un programa de radio aparece un hombre en el escenario que no se identifica con nitidez. El texto que aparece sobre la imagen ("Pero no pueden sospechar lo que es") y esta misteriosa aparición se encaminan a generar intriga en el espectador, el cual puede adivinar que se trata de un personaje importante por la expectación del público del teatro. Esta expectación se proyecta en el conjunto de la película y así se genera en los espectadores del tráiler expectación por la película promocionada. El hombre que entra en el escenario del teatro es Bobby Deglané $^{9}$ (que en la película se interpreta a sí mismo. Es un reclamo importante para el espectador debido a la gran popularidad del personaje.

\footnotetext{
${ }^{8}$ Hay que recordar que en estos años la radio era el principal medio de comunicación de masas. La vida familiar y social se organizaba en torno a ella, por lo que cualquier persona que viera el tráiler se sentir identificada con esta afirmación. Precisamente el plano que acompaña a este texto es el de una radio situada sobre una mesilla de noche junto a una cama, es decir, en un contexto doméstico

${ }^{9}$ Se trata de un famoso locutor de radio chileno con gran éxito en nuestro país en la década de los años 50. Se le considera el creador de los programas-espectáculo en la radiofonía española con programas tan populares como Cabalgata fin de semana (1951) y Carrusel deportivo (1954).
} 
A continuación una serie de fragmentos dialogados trazan de manera breve la trama de la película. Se presentan los protagonistas y las principales acciones. En una de las escenas aparece el popular Francisco Raval (que interpreta al presentador Gabriel Matilla) con la actriz Margarita Andrey (Carmen), otra de las estrellas de la cinematografía española de los cincuenta, en un plano americano. La escena tiene un tono marcadamente amoroso y en ella se da información relevante de la película. La popular cantante de copla Gracia Montes es la protagonista de otra de las escenas. La tonadillera se muestra con un plano medio cantando delante de un micrófono de radio. Precisamente Gracia Montes era en esos años una asidua de programas de radio musicales, solía intervenir en conocidos programas como Conozca usted a sus vecinos de Rafael Santisteban o Cabalgata Fin de Semana, que dirigía Bobby Deglané. Otro de los elementos destacables es que tras la fecha genérica del estreno de la película ("PROXIMAMENTE en este SALÓN"), se informa sobre la empresa productora del tráiler (“Un avance CÁNOVAS").

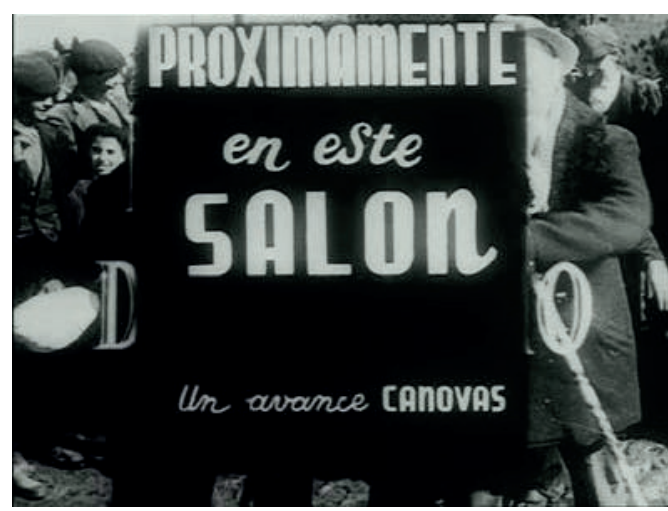

Figura 2. Avance del film Cánovas

La música que aparece a lo largo del tráiler corresponde a la pieza musical que inicia la película, una composición de Ernesto Halfter. Se trata de una pieza de carácter alegre y popular. Una escena en la que la música adquiere un papel principal es la de la cupletista Gracia Montes interpreta la canción La Romera. El montaje también es un elemento relevante en el tráiler. Se trata de un montaje paralelo con materiales heterogéneos referentes a los tres relatos independientes que aparecen en la propia película. Se muestran también imágenes de corte documental que potencian la referencialidad de las imágenes, influidas claramente por la comedia posneorrealista, como el caso de la primera imagen que muestra el apoyo de un pueblo entero a un vecino que concursa en un programa radiofónico. En lo que respecta a las transiciones entre los planos, se pueden destacar las cortinillas que se muestran de formas muy variadas (circulares, cuadradas, piramidales, etc.) que potencian la agilidad y dinamismo de este tráiler.

Respecto a la política de promoción el tráiler destaca como principal atractivo el director de la cinta, que se presenta en dos ocasiones ("Y un genial REALIZADOR" "JOSE LUIS SÁENZ DE HEREDIA" y "Bajo la dirección de JOSE LUIS SÁENZ DE HEREDIA"). El ilustre reparto también es resaltado por el tráiler. Aparece un listado de actores muy afamados de los cincuenta como Francisco Raval, José Isbert, Juanjo 
Menéndez o Tony Leblanc. Llama la atención la manera en la se muestra la aparición en la película de Francisco Raval, con una estética muy próxima a la de Humphrey Bogart en la película Casablanca (Michael Curtiz, 1942). El tráiler recurre al icono de uno de los galanes de Hollywood para situar al personaje interpretado por Francisco Raval en la película, protagonista de la historia amorosa del filme.

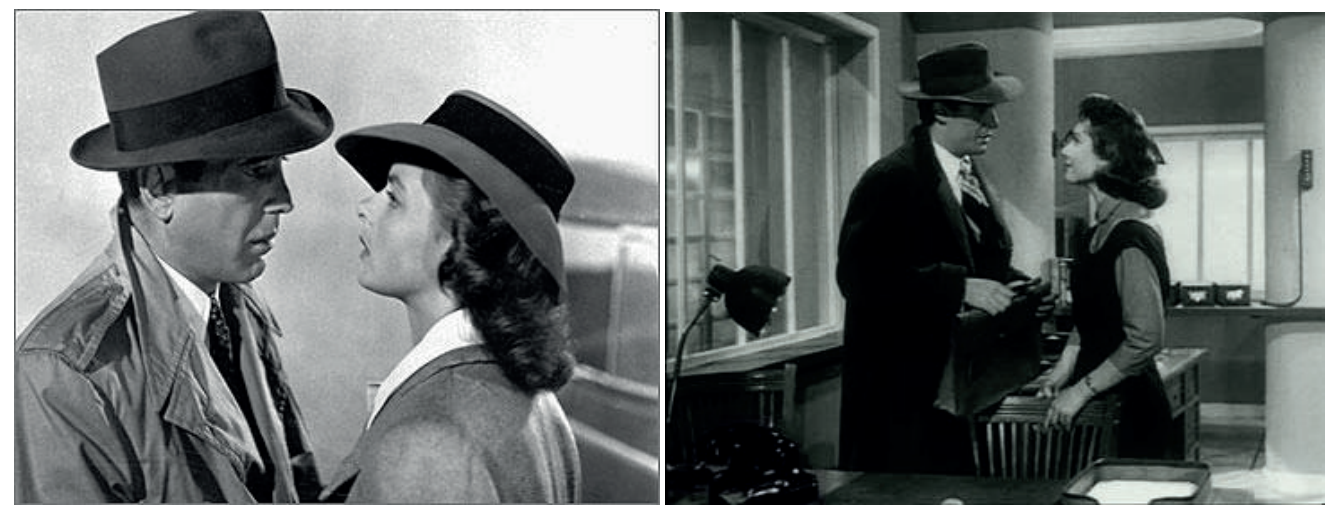

Figura 4. Casablanca (Michael Curtiz, 1942)

Por último el tráiler también recurre a los personajes populares que intervienen en la película interpretándose a sí mismos como el torero Rafael Gómez 'El Gallo', el futbolista Luis Molowni o el grupo musical 'Los Xey'. Especial relevancia tienen en el tráiler las apariciones del locutor Bobby Deglané y la de la cantante Gracia Montes.

\subsection{La década de los 60}

El cine español de los años sesenta va a estar marcado en la década de los sesenta por la irrupción de dos movimientos de cine joven que, siguiendo la estela de otros movimientos europeos e internacionales, buscan una renovación temática y estética: el Nuevo Cine Español y la Escuela de Barcelona.

El Nuevo Cine Español estuvo auspiciado por la administración, especialmente por José María Escudero, Director General de Cinematografía y Teatro, que apoyó a un cine joven con cierta voluntad renovadora formalmente, aunque con una temática tolerable por la censura. Este cine joven estaba representado en gran medida por los jóvenes directores surgidos de la Escuela Oficial de Cine. Uno de los máximos exponentes del Nuevo Cine Español es el director Carlos Saura, cuya ópera prima,Los golfos (1959, pero estrenada en 1962) se aproxima en gran medida al nuevo cine europeo.

Por su parte, la Escuela de Barcelona tenía un perfil mucho más experimental en sus formulaciones estéticas y un aire afrancesado frente al carácter italianizante del Nuevo Cine Español. La Escuela de Barcelona no tenía ningún tipo de voluntad comercial y estaba claramente influenciada por la Nouvelle Vague. Ejemplos de este cine son Fata Morgana (Vicente Aranda, 1965), Cada vez que. . . (Carlos Durán, 1967). Se trataba, tal y como apuntan Castro de Paz y Pena, "de un movimiento 
vocacionalmente europeo, por lo que esto representaba de modernidad y alejamiento de la realidad española -y de toda voluntad de influir en ella, dicho sea de paso-, situado en los márgenes del sistema" (2005: 49)

En 1965 se pone en marcha el Control de Taquilla que permite cuantificar por primera vez el volumen de la industria exhibidora española. Tal y como señalan Castro de Paz y Pena, en 1966 más de 400 millones de espectadores acuden a las salas de cine, cifra que da una idea de la posición que ocupa en esa década el cine como principal industria del ocio. En estos años en los que la televisión comienza a penetrar en los hogares, la industria necesita éxitos populares que atraigan a un gran número de espectadores. Son los años de títulos taquilleros como Un beso en el puerto (Ramón Torrado, 1965), La ciudad no es para mí (Pedro Lazaga, 1965) o La muerte tenía un precio (Sergio Leone, 1965)

Un director decisivo de esta etapa es Berlanga, que en estos años dirige sus dos obras cumbre, Plácido (1961) y El verdugo (1963). Plácido le valió una nominación al premio Oscar como mejor película de habla no inglesa, por su parte, El verdugo, que supuso un alegato en contra de la pena de muerte tuvo una gran repercusión nacional e internacional, siendo galardonada en Venecia con el premio de la Crítica Internacional.

\subsection{Tráiler de El Verdugo (1963)}

El tráiler de El Verdugo comienza con una escena que busca captar la atención del público y generar su simpatía a través de una imagen distendida: la llegada de un barco de turistas a la playa de Mallorca. En él se puede apreciar un grupo de mises con bandas que saludan a los ciudadanos que reciben alegres este bello espectáculo. Esta alegría es expresada por la actitud de los ciudadanos, que saludan contentos al barco, y por la música extradiegética de carácter jovial, que se escucha. El espectador es consciente de que el tráiler va a presentar una comedia. La cámara se sitúa entre estos ciudadanos que van a dar la bienvenida al barco, al igual que los espectadores de cine deben dar la bienvenida al espectáculo cinematográfico, la película de El verdugo.

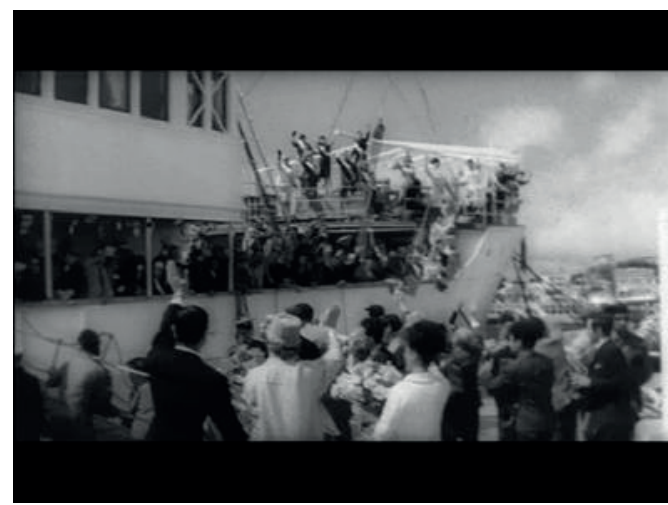

Figura 5. Ciudadanos que van a dar la bienvenida al barco de la la película de El verdugo 
La voz en off de un narrador introduce la trama que va a presentar la película promocionada: "A este hombre, ni bueno ni malo, ni mejor ni peor que otros, los imponderables de la vida le han puesto ante la trágica misión de ser verdugo, la cosa empieza así". Se trata de una breve presentación que viene ilustrada por una imagen cargada de un fuerte simbolismo que será clave en la película. Es la escena de las Cuevas del Drac de Mallorca. En un momento de la estancia en la isla, mientras el joven verdugo y su esposa asisten, como miles de turistas, a un espectáculo de luz y música, irrumpe en la cueva una barca con una pareja de la Guardia Civil, que viene a por José Luis para que ejerza por primera vez su macabro trabajo. El protagonista debe ir con ellos para ejecutar al reo. A continuación, a través de una serie de escenas dialogadas se traza el argumento de la película. La nota de humor tiene cabida en el tráiler: el popular José Luis López Vázquez, hermano del protagonista, mide la cabeza a su hijo, mientras la madre del niño (María Luisa Ponte) le dice: 'Que es normal! ¡Que ya te he dicho que es normal!, Que lo de mi padre no es hereditario". Una muestra del humor negro característico de Berlanga que invade toda la película.

De nuevo, la voz en off del narrador: "Patético e irónico dialogar entre seres envueltos entre la humana y la inhumana comprensión". Para ilustrar esta afirmación, el tráiler recurre a una de las secuencias de la película donde el patetismo del personaje se hace más palpable. Después de que el viejo Amadeo sorprenda en la cama a su hija Carmen y a José Luis, éste está preparando cara a una pared el discurso que va a pronunciar delante de Amadeo para pedir la mano de su hija. El narrador también ofrece el nombre del director de la cinta, el reparto y los galardones cosechados por la película: "El verdugo, la mejor y más característica película de Luis García Berlanga que ha obtenido el gran premio de la crítica internacional en el Festival de Venecia. Esta película ha sido interpretada por Emma Penella, que por este rol ha sido galardonada con el premio a la mejor actriz. Comparten el éxito en el reparto Nino Manfredi, José Isbert y José Luis López Vázquez". Los premios crean una buena predisposición hacia el film, especialmente en el público no objetivo de la obra. En este caso el Festival de Venecia se convierte en un gran reclamo para el espectador del tráiler. Esta locución es apoyada por texto escrito con los nombres del director y de los personajes, con letras blancas sobreimpresionadas y por imágenes de los actores protagonistas del film.

El tráiler concluye con información de la productora y la distribuidora. Además, se señala el éxito tanto de taquilla como de la crítica que está teniendo hasta ese momento la cinta: “El verdugo está siendo aplaudida por todos los públicos y proclamada una de las mejores películas europeas, siendo producida por Naga Films y distribuida en España por la prestigiosa marca C. B. Films". Esta parte acaba con el título de la película sobre la imagen que se corresponde con el final de la película. Con esta imagen Berlanga acaba con cualquier esperanza para el protagonista no sólo en el tráiler, sino también en el film. El barco que zarpa en el último plano, en el que aparecen jóvenes bailando sin ataduras, es una metáfora visual de su libertad, que de forma definitiva se le escapa. Mientras, el joven verdugo se queda en tierra firme con la cabeza gacha y la gorra tapándole la cara sin poder decirle nada a su mujer. Por último, se muestra la fecha genérica del estreno en esa sala cinematográfica: 
"Próximamente en esta pantalla". También hay una referencia a la empresa encargada de la edición del tráiler: "Selección de escenas por CATALÁ".

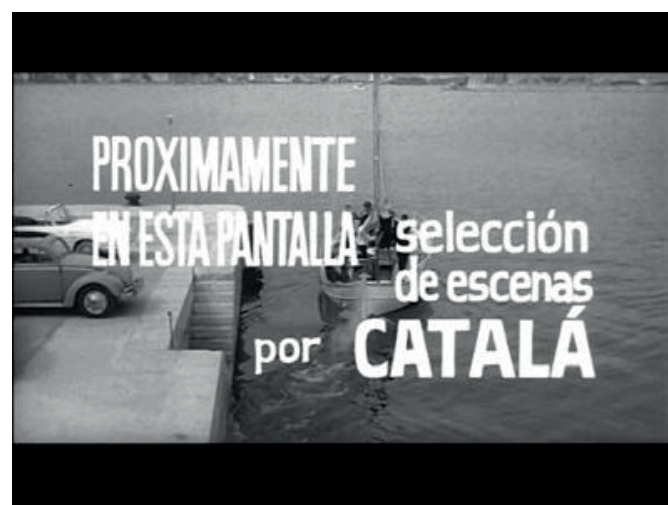

Figura 6. Selección de escenas por CATALÁ

La música que acompaña las escenas del presente tráiler forma parte de la banda sonora de la película, compuesta por Miguel Asins Arbó. Crea un efecto anempático o de contrapunto, ya que la música es indiferente con respecto a la situación emocional de las escenas, la misma melodía puede escucharse en escenas del tráiler dramáticas y cómicas. Por lo que respecta a las transiciones, abundan las cortinillas de formas variadas: estrelladas, de espiral, circulares, etc. que aportan gran dinamismo al montaje.

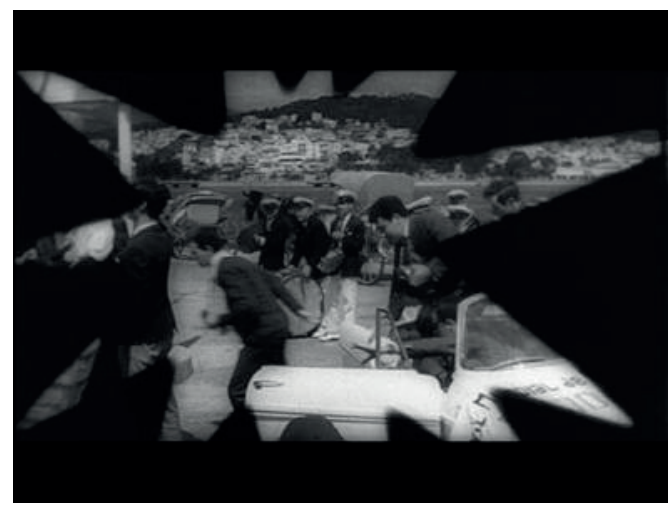

Figura 7. Transiciones: cortinillas de forma estrellada

En la política de promoción del tráiler se opta por darle mayor relevancia al director, Luis García Berlanga, que ya en ese momento es un director de prestigio ${ }^{10 .}$ En el tráiler también se destaca que la película ha obtenido el premio internacional de la crítica en el Festival de Venecia, un argumento muy relevante, pues supone el apoyo de la crítica internacional a la cinta de Berlanga. Los actores también tienen un peso específico en la política de promoción de la política. En primer lugar, hace referencia a Emma Penella "que por este rol ha sido galardonada con el premio a la mejor

10 Berlanga, cuando dirige El Verdugo, ya ha conseguido importantes galardones nacionales e internacionales: Primer Premio Concurso del Sindicato Nacional del Espectáculo por Familia provisional (1950), el premio del Festival de Cannes por Bienvenido Mister Marshall! (1952), el Premio de la OCIC del Festival de Venecia por Calabuch (1956) y la nominación al Oscar por Plácido (1961). 
actriz" (Penella obtuvo por su trabajo en El verdugo el Premio del Sindicato Nacional del Espectáculo (1963). Otro de los actores destacados en el tráiler es Pepe Isbert, enormemente popular por interpretaciones magistrales en destacados títulos como Bienvenido, Mr. Marshall (1953) o Los jueves, milagro (1957), ambas de Berlanga.

\subsection{La década de los 70}

Los años de la transición hacia la democracia fueron un periodo muy fructífero para el cine español11. Siguiendo la clasificación establecida por Julio Pérez Perucha y Vicente Ponce, existen cinco tendencias claramente diferenciables en el cine español de esta década: el landismo, el cine metafórico, la tercera vía, el cine político y el cine independiente. (Perucha y Ponce, 1985: 34 y 35). El cine de la década de los setenta es un cine acorde con los años convulsos de esa España predemocrática. Las películas se escapan del relato tradicional, desde los subproductos conocidos como 'S' a producciones que entran en el campo de lo experimental, documentales que repasan el pasado reciente franquista, cine underground, etc. Al igual que en otros ámbitos de la vida, se van conquistado progresivamente más libertades en el campo cinematográfico, lo que culmina con la abolición de la censura en 1977 y el estreno de filmes hasta entonces prohibidas en España como Viridiana de Luis Buñuel.

Muchos autores sitúan el inicio de este nuevo periodo cinematográfico en la película El espíritu de la colmena (1973), dirigida por Víctor Erice y producida por Elías Querejeta. La película es una muestra de un "realismo elíptico que hablaba de la posguerra y del franquismo sin ningún tipo de filtro discursivo". El film obtiene en septiembre de 1973 la Concha de Oro del Festival de San Sebastián, con lo que inaugura una nueva era para el cine español.

\subsubsection{Tráiler El espíritu de la colmena (1973)}

La película El espiritu de la colmena transcurre en un pueblo de la Mancha en los años de posguerra. Su tráiler comienza con una imagen blanca de la pantalla en la que se indica el productor de la película, Elías Querejeta. A continuación otra imagen de una vía del tren y dos niñas. Una de ellas está de pie justo en el centro de las vías, mientras la otra tiene su cabeza apoyada en una de las vías. El color y la composición de la imagen, junto con la música remiten a un ambiente onírico, desconcertante para el espectador. Una voz en off contextualiza de forma peculiar la acción del film: "Año 1940, un pueblo cualquiera de la meseta castellana".

A continuación, sobre imágenes de las dos niñas en las vías del tren, la voz del narrador apunta: "El espíritu de la colmena: Una visión sensitiva y poética del mundo de los niños y de su aislamiento en el interior de la familia y la sociedad". Esa presentación representa una síntesis de la naturaleza de la película. A continuación

\footnotetext{
11 “En los diez años que median entre 1973, con los primeros estertores del franquismo y la aparición de una serie de de películas que anticipan el cambio de régimen, y 1982, año del triunfo del PSOE en las elecciones generales de octubre, se producen del orden de mil películas de largometraje" (Castro Y Pena, 2005: 59
} 
aparece el título de la película extraído de los créditos del film. Simboliza el oficio del padre de las niñas (Fernando Fernán-Gómez), que es apicultor. Los títulos de crédito de la películas están construidos sobre la base de dibujos de párvulos -la autoría es de Ana Torrent, Isabel Tellería y sus hermanos-, lo que nos introduce en un universo de cuento infantil, pieza clave de la película.

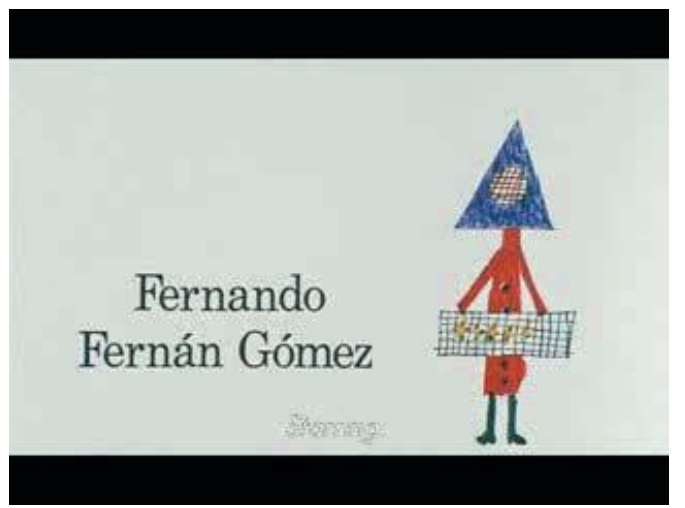

Figura 8. Oficio del padre de las niñas (Fernando Fernán-Gómez)

Más adelante, la voz del narrador elogia la película señalando algunas de las cuestiones planteadas por el film: "El espíritu de la colmena: un canto a la imaginación, a la fantasía en una historia auténtica. Los porqués de una niña, su querer saber, sus primeras preguntas y sus primeras respuestas". Estas palabras se apoyan con imágenes de la película que muestran a los miembros de la familia: el padre, las niñas y la madre y la casa en la que viven.

El final del tráiler se limita a mostrar, también con los títulos de crédito infantiles, el nombre del director, Víctor Érice, acompañados del dibujo de un reloj de cadena. En la película, este reloj pertenece a Fernando, el padre, y cada vez que lo abre suena una melodía. Precisamente los títulos de crédito de la película ya anticipan una serie de objetos primordiales en la película como la colmena, el apicultor, las cartas o el reloj. El tráiler ofrece una estructura difusa, los límites entre las partes que lo componen resultan algo difusos. Esto está en sintonía con el resto de la película que tiene, como señala Juan Miguel Company, "una clara voluntad poemática y musical" (Perucha, 1997: 711) ${ }^{11}$

Respecto a la banda sonora, El espíritu de la colmena es una película de silencios, que en este caso son tanto o más expresivos que las palabras. Esta idea también se manifiesta en el tráiler. Los diálogos quedan reducidos a la mínima expresión, pues prácticamente se reducen a los de las niñas. Este silencio produce unas veces quietud, calma y otras veces angustia y se puede entender como un brindis al cine mudo, que con sus limitaciones era capaz de transmitir tantas emociones como el sonoro. El ejemplo es este tráiler que, con una ausencia casi total de sonido, se convierte en un tráiler de un alto grado de expresividad.

Por lo que respecta al montaje, lo más llamativo del tráiler son sus encuadres y sus casi imperceptibles movimientos de cámara. Abundan los planos fijos y los encuadres 
inalterables. Además de estos planos fijos con profundidad de campo, también hay travellings suaves que ayudan a contemporizar la narración. El orden de las escenas en el tráiler no se corresponde con el orden cronológico de la película e incluso el montaje altera el sentido del film provocando con la alteración del orden de las escenas en el tráiler una comprensión errónea del argumento de la película: todo parece indicar que los disparos que se escuchan matan a la pequeña Ana, que aparece en la siguiente escena tumbada en el suelo. En la película, los disparos no acaban con la vida de Ana, sino con la del fugitivo.

En el montaje del tráiler también se percibe el trayecto protagonizado por Ana en la película, desde la confrontación de la primera parte de la película en la que la niña interroga sin cesar a su hermana y a los adultos buscando respuestas (en el tráiler esta parte queda representada con la escena de la habitación de las niñas en las que Ana pregunta: “¿Por qué el monstruo mata a la niña y por qué le matan luego a él?") a otra segunda en la que el mutismo de Ana sólo se romperá con la palabra "ten", en un gesto de solidaridad con el fugitivo, cuando la pequeña le da la manzana. En el tráiler este mutismo es subrayado todavía aún más ya que se puede ver como Ana pronuncia la palabra "ten" delante del fugitivo, pero no se puede oír. La palabra es sustituida por la música.

De la política de promoción puede señalarse que el tráiler le da un lugar destacado al productor de la película, Elías Querejeta, que abre la pieza promocional. Querejeta es uno de los principales productores de nuestro país y ha participado en más de cincuenta películas, de las que una buena parte contribuyen a la renovación de los temas y las formas del cine español del tardofranquismo y la transición. Entre ellas destacan La prima Angélica (1973) y Cría cuervos (1975), galardonadas con el Premio del Jurado en el Festival de Cannes. Otro elemento que destaca el tráiler es el reparto, señalando los nombres de los actores protagonistas: Fernando Fernán Gómez, Teresa Gimpera y las niñas Ana Torrent e Isabel Tellería.

\subsection{La década de los 80}

En 1982 Pilar Miró accede al puesto de Directora general de Cinematografía. Mediante el Decreto Le de 1984, conocido como 'Ley Miró' se promoverá un cine de calidad a partir de un sistema de ayudas claramente influenciado por el modelo francés de subvenciones anticipadas. Este cine de calidad se encaminará hacia un mejor acabado industrial próximo al europeo. Este nuevo cine español suele ejemplificarse con la película de Mario Camús de 1984 Los santos inocentes, adaptación de la obra homónima de Miguel Delibes.

En estos años también proliferan películas sobre la guerra civil y el franquismo como El viaje a ninguna parte (Fernando Fernán Gómez, 1986), Si te dicen que caí (Vicente Aranda, 1989) o Padre Nuestro (Francisco Regueiro, 1985). Otros directores como Pedro Almodóvar (Mujeres al borde de un ataque de nervios, 1988), Fernando Trueba (Sé infiel y no mires con quién, 1985) o Fernando Colomo (La vida alegre, 1987) son los máximos exponentes de la comedia en esta década. Son películas que conceden una 
gran importancia al diseño de producción, lo que supone el gran signo distintivo y de ruptura con la comedia de los años anteriores.

En esta tendencia destaca el manchego Pedro Almodóvar que evolucionará desde el espíritu transgresor de sus primeras películas a un cine de gran estilización fundamentado en el melodrama, y más concretamente en los women pictures del Hollywood clásico. Éste es el caso de la película ¿Qué he hecho yo para merecer esto? (1984) protagonizada por Carmen Maura, Verónica Forqué, Gonzalo Suárez, Ángel de Andrés Lépez, Amparo Soler Leal y Emilio Gutiérrez Cava. La película muestra,como señala Luciano Berriatúa, "el retrato posiblemente más patético que hayamos visto en el cine español de la condición femenina en nuestra sociedad deprimida y represora".

\subsection{1 ¿Qué he hecho yo para merecer esto? (1984)}

La primera imagen del tráiler hace referencia a las productoras del film, Tesauro y Kaktus, que se presentan en letras blancas sobre un llamativo fondo rojo, una de las señas de identidad de la cinematografía de Almodóvar. El tráiler traza la historia de Gloria, una ama de casa, madre de dos hijos, esposa de Antonio y nuera de una mujer de campo que no se acostumbra a vivir en la ciudad. Trabaja como asistenta por horas y se ocupa de las labores del hogar. Toda la familia vive en los umbrales de la pobreza con grandes dificultades para hacer frente a los pagos básicos del mantenimiento familiar.

En el tráiler se incluye un extracto de la actuación musical en televisión del propio Almodóvar y McNamara escenificando la versión de Miguel de Molina de La bien pagá.\} Con la yuxtaposición de los planos de Gloria y el personaje de la copla se produce una identificación de tipo irónico entre La bien pagá y la protagonista. La identificación también se produce por el contraste entre la dejadez física de Gloria, que atareada con todas las labores domésticas, no tiene tiempo de prestar atención a su físico y la cuidada imagen de la protagonista de la copla, que aparece pintándose de manera coqueta los labios. La referencia a esta actuación se repite más adelante en el tráiler. Esta vez la escena recrea un ambiente kitsch y homenajes a la anteriores películas del director: Pepi, Luci, Bom y otras chicas del montón y Entre tinieblas a través de sus carteles, situados al fondo de la escena.

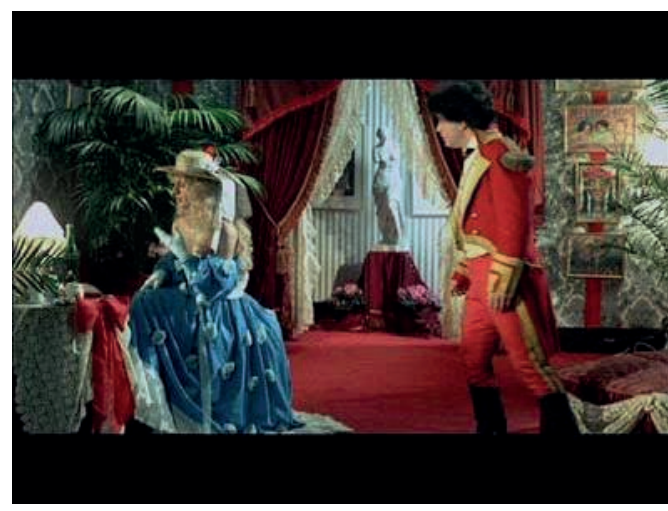

Figura 9. La bien pagá 
La banda sonora delimita las partes del tráiler. En primer lugar, la versión de La bien pagá presenta a la protagonista, Gloria, y se establece brevemente el argumento del film. La inclusión en la película de esta representación responde a un gusto por el camp que Almodóvar ha manifestado desde sus primeros trabajos. La segunda pieza, en este caso compuesta por Bernardo Bonezzi, está situada en el final del tráiler. Tiene un carácter triste que subraya la soledad que siente la protagonista con lo que se produce una conexión emotiva de la música con la protagonista.

Por lo que respecta a la política de promoción se ha optado por darle mayor relevancia a la actriz protagonista, Carmen Maura, que está presente en casi todas las escenas del tráiler y, además, es la única actriz del reparto que figura en el texto del mismo. En 1984, fecha en la que se estrena ¿Qué he hecho yo para merecer esto? Carmen Maura comienza a conocer la popularidad de la mano de Almodóvar, tras aparecer en sus primeras películas: Pepi, Luci, Bom y otras chicas del montón y Entre tinieblas.

Otro elemento destacado en el tráiler es el director de la cinta, Pedro Almodóvar. Su nombre aparece escrito en la escena final del tráiler sobre un plano de Carmen Maura, su actriz fetiche en estos años. Además es destacable la aparición del propio director en la representación teatral de la copla La bien pagá que se incluye en el tráiler junto a otro de los personajes más populares de la movida madrileña, Fabio McNamara. En este momento el director Pedro Almodóvar es uno de los rostros más representativos de la movida gracias a sus anteriores filmes (Pepi, Luci, Bom y otras chicas del montón, Laberinto de pasiones y Entre tinieblas).

\section{CONCLUSIONES}

Después de analizar algunos de los trailers más representativos de las décadas de los

50, 60, 70 y 80 de la cinematografía española, se puede establecer una evolución de esta pieza promocional a lo largo del tiempo. Este progreso ha sido muchas veces paralelo al del tráiler en Hollywood, industria de cine más potente a nivel internacional.

Tal y como se ha comentado, en sus inicios el tráiler era un simple fragmento extraído de la película promocionada o la primera parte del film que se exhibía con el objetivo de llamar la atención del espectador sobre la cinta y despertar en él la curiosidad sobre la historia presentada. Poco a poco los trailers fueron adquiriendo más importancia y se convirtieron en la pieza clave de la promoción cinematográfica hasta ser hoy en día el elemento central de la campaña promocional de una película. Comienza entonces la profesionalización de los trailers en la década de los cincuenta, cuando pasan a estar en manos de montadores especializados produciéndose con ello la estandarización de estas piezas audiovisuales.

En la década de los cincuenta destaca en la edición de los trailers la gran cantidad de texto escrito en grandes letras blancas dirigido directamente al espectador de la sala de cine ("USTEDES, claro está, deben ser todos RADIOYENTES"). El texto tiene una importancia capital, es el hilo conductor del tráiler, mientras que las imágenes se 
limitan a ilustrar la información aportada a través del texto escrito. Se subraya también la aparición de reconocidos actores, característica que se mantiene a lo largo de la historia del tráiler. Por otra parte se emplean frases grandilocuentes paraexaltar la película ("Pero no pueden sospechar lo que es, la más ORIGINAL PELÍCULA del momento, HISTORIAS DE LA RADIO"). En el montaje lo más relevante en la década de los cincuenta es el uso de llamativas cortinillas para la separación entre plano y plano.

Estas características pueden observarse también en los trailers de las producciones norteamericanas de los años anteriores, como por ejemplo, El halcón maltés (John Huston, 1941) o Casablanca (Michael Curtiz, 1943), en los que se pueden leer textos con grandes letras blancas sobre escenas de la película: "If you are looking for adventure, you will find it in CASABLANCA". En estos trailers también se destaca la presencia de las estrellas de la película y utilizan, al igual que sucede en los trailers españoles, llamativas cortinillas para separar los planos.

Tal y como señala Claudia Melissa Neves, algunos trailers van a suponer una revolución en la edición de las piezas promocionales cinematográficas, estableciendo nuevas pautas en la realización. Así, el tráiler de Teléfono Rojo, volamos hacia Moscú (Stanley Kubrick, 1964) provoca una auténtica transformación de la gramática audiovisual de los trailers. En él se intercalan textos con escenas de la película. Frame por frame el avance presenta varias preguntas que son completadas en algunas ocasiones o respondidas por los personajes de la película. Forma una estructura en la que se mezclan el sonido, el texto y las imágenes. Además, el tráiler sigue un esquema que no se corresponde con la estructura dramática de la película. Muestra claramente uno de los principales temas de la película, los problemas de comunicación entre estos tres espacios a partir del montaje: los diálogos resultantes de superponer las escenas y los textos resultan caóticos y carentes de sentido.

Al igual que sucede en Hollywood, en España, a mediados de la década de los sesenta, los estudios comienzan a invertir en la modernización de los trailers. Los nuevos profesionales abandonan la tradicional forma de edición, basada en la continuidad, linealidad y transparencia por una nueva estética como puede observarse en el tráiler analizado de El espíritu de la colmena, en la que se prima la mostración de la estética onírica y el contenido metafórico del film en detrimento de la trama, llegando incluso a plantear un final equívoco en el avance como síntoma del abandono de la tradicional linealidad en el montaje.

La década de los setenta supuso para la industria cinematográfica de Hollywood el reconocimiento de la televisión como instrumento de innegable importancia para las campañas de marketing de cine. Los trailers comienzan cada vez más a adoptar el lenguaje de los spots publicitarios de la televisión. Ello contribuye a una nueva modificación de su estética, que se torna más agresiva, aumentando la velocidad de edición y otorgando una mayor relevancia a la banda sonora. Todas estas características se manifiestan en los trailers de las películas de producción española en los años ochenta. 
Así, el tráiler de ¿Qué he hecho yo para merecer esto? comienza con un guiño al medio televisivo con la actuación del propio Almodóvar y Fabio McNamara interpretando la copla La bien pagà en la televisión de la casa de la protagonista. El montaje además es mucho más acelerado que los trailers de años anteriores y su duración se acorta notablemente: Frente a los más de tres minutos de los trailers de la década anterior (tres minutos y treinta y un segundos en El espíritu de la colmena), los trailers de estos años raramente llegan a los dos minutos de duración, como el caso de ¿Qué he hecho yo para merecer esto?, que tiene una duración de un minuto y medio.

La década de los ochenta traerá una nueva revolución de la mano de la cadena norteamericana MTV (Music television) que modifica el lenguaje de la televisión, de la publicidad, de las artes gráfica y también del tráiler. Este canal, cuya base de la programación se encuentra en los videoclips, impone a través de su lenguaje acelerado un nuevo estilo de edición y una nueva forma de asimilar la información por parte de los espectadores, más información en menos tiempo.

Esto supone para la práctica del tráiler dos importantes cambios: por un lado puede ofrecerse más información sobre la película en menos tiempo y, por otra, se pueden esconder de manera más fácil lo defectos. Tal y como apunta Neves, "una vez establecido este estilo de corte rápido, se elimina el juicio cualitativo que existía en la edición más lenta. Y como parte del tráiler es esconder, no revelar franquezas inherentes al film, el corte rápido es una buena manera de hacerlo" (Neves, 2006, 76)

Otra característica de los trailers españoles de la década de los ochenta, también debido a la influencia del videoclip, es la desaparición de la voz en off del narrador. Hasta este momento era un recurso muy empleado en las piezas promocionales de producción española, como los casos de El verdugo (1963) o El espíritu de la colmena (1973). A partir de este momento la voz en off se sustituirá por la banda sonora o los diálogos, que se convertirán en el único hilo conductor de los trailers.

\section{REFERENCIAS}

Castro, J.L. \& PENA, J.J. (2005). Cine español, otro trayecto histórico, Nuevos puntos de vista. Una aproximación sintética. Valencia: Ediciones de la Filmoteca.

Debruge, P. (2002). A brief history of the trailer en Movie Trailer Trash. Consultado el de Agosto de 2011, de http:/ / www.movietrailertrash.com.

Dornaleteche, J. \& GIL, E. (2011): Mash-ups, re-cuts y fake trailers: manifestaciones mediáticas del consumidor contemporáneo. IV Congreso de Análisis Fílmico, Castellón.

Dornaleteche, J. (2007). Definición y naturaleza del trailer cinematográfico. Pensar la publicidad, I, (2): 99-116. Consultado el 27 de Julio de 2011, de

http:/ / revistas.ucm.es/inf/18878598/articulos/PEPU0707220099A.PDF. 
Dornaleteche, J. (2009). El trailer cinematográfico: historia de un género publicitario en EE. UU. Pensar la Publicidad, III, (1): 163-180.

Hediger, V. (2003). A cinema of memory in the future tense: Godard, trailers and Godard trailers. En Williams, J.; Temple, M.\& Witt, M. (Eds.). Forever Godard: the work of Jean-Luc Godard, 1950 to the present. Londres: Black Dog Publishing.

Kernan, L. (2004).Coming Attractions: Reading American Movie Trailers, University of Texas Press.

Martínez Puche, S. (2008). El tráiler de cine: entre el spot publicitario y la demostración narrativa. El caso de el bosque. Revista do NP de Comunicaçao Audiovisual da Intercom, 1, (2), Consultado el 1 de Agosto de 2011, de http://ojs.portcom.intercom.org.br/index.php/NAU/article/viewPDFInterstitial/5 $\underline{363 / 4931 .}$

Neves, C. (2004). Trailer: Cinema e publicidad no mesmo rolo. Un estudo sobre o trailer e o movie marketing, ilustrado pela campanha de lançcamento do film Cidade de Deus. Tesis Doctoral, Universidae federal Fluminense. Recuperado el 20 de julio de 2011, de

http:/ / www.bdtd.ndc.uff.br/tde_busca/arquivo.php?codArquivo=1133

Pérez Perucha, J. (Ed.) (1997). Antología crítica del cine español 1906-1995: Flor en lasombra. Madrid: Cátedra.

Thomas, K. (1966). Movie Trailers Have Long Run en Los Angeles Times, 25 October 1966, Part IV.

\section{Eva María Gil-Pons}

Licenciada en Comunicacción Audiovisual por la Universidat de València. Actualmente realiza su tesis doctoral sobre la narrativa del tráiler cinematográfico en la Universidade da Coruña donde colabora en la docencia de las materias Narrativa Audiovisual, Ficción Contemporánea y Comunicación Oral y Escrita. 